\title{
COMPUTER MODELLING OF HUMAN SITUATION AND BEHAVIOUR IN FIRE
}

\author{
Petr KUČERA ${ }^{1}$, Miroslav ANTONÍN ${ }^{2}$
}

Vision paper

Wbstract: $\quad$ When assessing a safe object evacuation in case of fire development, there is an applicable
alternative way of project design to simulate human egress using the mathematical
modelling of fire. The article is therefore focused on the case simulations of people's
evacuation in fire. Basic data about simulation environment are addressed, as well as the
conditions of fire, the characteristics of persons or development, and the assessment of two
simulations. The introductory part of the article is devoted to the basics of mathematical
formulation of human movement and behaviour during actual evacuation.
Evacuation, Fire, Mathematical modelling, Human behaviour, Toxicity.

\section{Introduction}

We currently live in a time when fire safety of buildings and fire prevention are significant concerns. A considerable development in this area occurred in the last several decades and the field is constantly developing. Enormous effort is put into the prevention of fire or its subsequent spreading, but there are still situations in real life when one can't prevent these incidents completely. In most cases, several simultaneous factors may occur that one doesn't foresee and that can't be ruled out even by the best standards. Therefore, it is important to take these aspects into account and reckon with the worst possible scenario or, better still, prepare for it.

Computer simulation programs can provide a prospective way of achieving this goal . Many of them are available in the present time and the choice depends predominantly on the specific fire or evacuation situation which should be analysed. Obviously, one can use them not just for critical scenario projection, but also for reverse simulation when these programmes may help to discover the cause of the fire. However, we should know well the mechanisms and mathematical apparatus that the particular programme uses in order to utilise all the available information and so that the simulation could approximate the real situation.

The human safety should be always the major concern, that's why such simulation programs are developed that focus on modelling human movement and behaviour. Some of them address just human movement without influence of fire, which may be useful for assessing the time that people need to escape from building with complex structure.
More flexible, though, are applications which make possible to connect the model of fire with evacuation. The latter way can relate fire impact to human behaviour that is naturally influenced by fire.

It's not easy to implement these factors into simulation programmes, because every person reacts to impulses in his/her individual manner. Therefore, this field is constantly improving. In order to achieve new findings and data, experimental evacuations are performed that provide useful information.

\section{Materials and methods}

Simulation programmes for human egress can be divided into many groups according to various viewpoints. From the point of view of model procedures, the evacuation models can be sorted into three categories (Folwarczny and Pokorný, 2006):

- description of basic aspects of behaviour or movement using equation or equations,

- description of various aspects of human movements,

- connection between movement and behaviour.

The latter mentioned category, which is the main theme of this article, doesn't take into account just the characteristics of the spaces. It also views the individuals as active objects and takes into consideration their individual reactions to given impulses. These models are characterized mainly by high level of complexity and elaboration. Basic data about the aspects of human behaviour are constantly explored using trial evacuations, and the new findings offer a valuable basis for improving the simulation programmes. Following partial sections

\footnotetext{
VŠB - Technical University of Ostrava, Faculty of Safety Engineering, Ostrava, Czech Republic, petr.kučera@vsb.cz

2 VŠB - Technical University of Ostrava, Faculty of Safety Engineering, Ostrava, Czech Republic, student
} 
provide basics of mathematical modelling of human movement and behaviour during evacuation (Hostikka, 2007). The given theoretical grounds are implemented in simulation software FDS+Evac, which served as a tool for simulations in exercises.

\section{Movement of persons in simulation}

Simultaneous egress of more persons from a room or building can cause life endangering situations. For example, the problem occurs when crowd is obstructed by narrow passage or blocked exit (due to many persons), which inhibits quickness of the persons in the front of the crowd. The rest of the crowd tends not to stop moving forward and it can block the exit completely. Even a slight pressure from the end of the crowd, which tries to move forward constantly, can cause fractures to people in the front. Other kind of trouble can be when some persons fall down a make the evacuation harder to other people. The ability to identify these dangerous situations is very important in modelling.

In order to simulate the above mentioned situations in a realistic way, it's significant for simulation software to work with real physical forces which can result from situations like these. The main factors that should be taken into account are body's resistance to pressure and friction forces among persons or among persons and obstacles. In the programme FDS+Evac every person is directed by his or her own movement (1) (Hostikka, 2007). This procedure enables all simulated individuals to have their own exit strategy.

$$
m_{i} \frac{d^{2} x_{i}(t)}{d t^{2}}=f_{i}(t)+\xi_{i}(t)
$$

Where

$m_{i} \quad$ the weight of a person,

$x_{i}(t)$ the position of the person at given time,

$f_{i}(t)$ the force that impacts on a person at given conditions,

$\xi_{i}(t)$ the small random fluctuation force,

$d x / d t$ the speed of a person's movement.

Getting the mentioned coefficients leads to other relatively complex equations which include important factors (reaction of person to fire, contact with obstacle or other person, etc.).

The shape of human body is represented in simulation equations by three of mutually connected circles (Korhonen and Hostikka, 2009). So, it implies some rotary degree of freedom, when every person has his or her own rotary equation.

\section{Choice of emergency escape}

In a model situation, every person considers position and activities of other escaping people and chooses, by guess, the emergency escape which would help him or her to evacuate fast. Expected time of evacuation consists of the estimation of movement time and the time of queue formation. The movement time is calculated as a quotient of distance to door and the speed of movement. Calculated time, which depends on queue formation and queuing into them, is a function of activities of other escaping persons. There is also an assumption that people change their behaviour only if they have a better option.

Besides location of escape exits and the other people's activities, there are more factors that should be taken into account. The issues are the conditions related to fire and the person's awareness about location of escape exits and their visibility.

On the basis of all the mentioned factors, the escape exits can be divided into seven groups and certain preferences are assigned to them (Hostikka, 2007). Knowledge of escape exits can be generated randomly or every simulated person may get it arbitrarily. The visibility of escape exit depends on the density of smoke and also on the location of obstacles. The choice of preferences then depends on conditions related to the effects of fire, like temperature and smoke, which have adverse impact on escaping persons, but they aren't fatal.

Knowledge of escape exits location is the main factor that affects decision making. It's due to unknown conditions that could occur on unfamiliar emergency escape route and thus increase danger. Escaping persons prefer to use known emergency escape route even if faster routes are available but unfamiliar to them.

\section{Groups}

Crowd consists of partial groups (e.g. families) which have the tendency to act together. In model situation, the groups' activities can be divided into two phases, one being the collecting phase in which the persons are gradually grouped, and the second phase, in which the group is already moving together along the chosen escape route.

In the collecting phase, the persons try to move towards the centre of the group. If the distances among the centre of the group and all other moving persons are below required limit, the group is considered to be complete and it starts to move towards the escape exit. While in the move, the members of the group try to stick together in order not to disintegrate. This is simulated by the necessary 
correction of the person's walk speed and by adding the additional force which acts towards the centre of the group. The force is called group force and its intensity determines how much the escaping persons try to hold the group together, which can differ from one group to another. For example, the group that consist of mother and child should have more group force than the one consisting of work friends.

\section{Simulation of evacuation in fire environment}

The aim of this part of the article is to put together exercises in which the evacuation is connected to the model of fire. This task was executed using the software Fire Dynamics Simulator (hereinafter referred as FDS) and auxiliary module Fire Dynamics Simulator with Evacuation (hereinafter referred as FDS+Evac), while FDS itself serves for creating the geometry of space and the conditions of fire. Auxiliary module enables the simulating the evacuation in the created environment.

The main theme of this work is the situation of a fire originating in a night club. The subject of simulation is the development of heat with simultaneous emission of toxic fumes that represent the fire and the development of the night club guests evacuation. To give illustrative example, two exercises were crated which differ in intensity of given fire and its location in the room (see Fig. 1). This gives an opportunity to compare the influence of fire on escaping persons that are located in the same room, but they are submitted to distinct effects of fire on different locations.

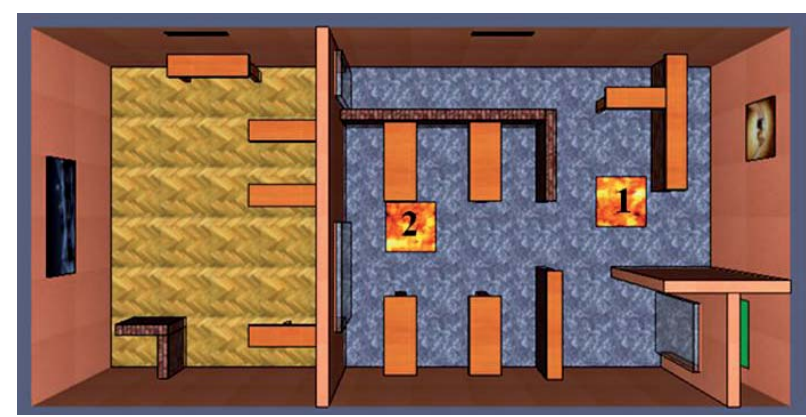

Fig. 1 Depiction of the room for simulation and location of the fire

\section{Description of the room}

The object chosen for the simulation is a night club with the size of $6 \times 12 \times 3 \mathrm{~m}$. The inner layout of the object is derived from several existing night clubs. There is only one entrance into the object, which also represents the only escape exit. The club is divided into the room with dance floor and the barroom. Both rooms are furnished and the furniture forms evacuation obstacles. Ventilation system for the purpose of simulation is adjusted in a common way. It consists of just two air shafts under the ceiling with the size of $1 \times 0.2 \mathrm{~m}$. There is only one in every room. The floor of the dance room is classic parquet floor $1 \mathrm{~cm}$ thick, while in the bar-room there is a concrete floor with load carpet $6 \mathrm{~mm}$ thick.

\section{Materials used and their physical properties}

All the walls, room dividers, floor (before surface treatment) and ceiling are made of concrete panels, while their surface finish isn't taken into consideration, with the exception of floors. Low dividing wall in the bar-room, the base of bar and space for music band service are made of bricks. Table, bar and parquet blocks are made of the same wood material. For all the mentioned materials, regular physical properties were used.

\section{Simulated fire}

In order to simulate the evacuation after the fire developed, the most important part is the development and spread of the toxic emissions of fire, to which simulated persons react. In the following practical simulations, the designed fire does not spread gradually in the given space and does not take progressively more area. Fire is simulated in the area of $1 \mathrm{~m}^{2}$ and, dependently on time, its intensity grows and with it the development of toxic emissions.

The rate of heat release during time $Q$ was calculated using simple quadratic equation (ČSN, 2004) in different time steps and subsequently put into the source code of the programme which was able to calculate all the values for the remaining time intervals. The result was time dependent parabolic curve in which the rate of heat release is related to the second power of time. Growth $t_{\alpha}$ was calculated using fire load $p$ and speed of carbonization coefficient a in accordance with (ČSN, 2009).

The values $a_{n}$ a $p_{n}$ from A annex of ČSN 730802 were considered for simulation. They refer to the ball room, where $a_{n}=1.2$ and $p_{n}=15 \mathrm{~kg} \cdot \mathrm{m}^{-2}$. Tab. 1 from (ČSN, 2009) was used to determine the value $p_{s}$, the coefficient as has a constant value of 0.9. Because this is not strictly the case of ball room space, it was also necessary to calculate the values $a_{n}, p_{n}, p_{s}$ and the final rate of carbonization coefficient more accurately. After elaborate calculation, the resulting value $Q$ was lower than when using standard values. However, a higher value of $Q$, based on simplified calculation and standard values, was used to 
simulate fire. As final fire doesn't reach too high temperatures, less toxic emissions, to which the escaping persons react primarily, are present. That's why the higher value of $Q$ resulting from the two possible calculation methods was chosen.

The following graph for expected simulation time of 200 seconds enables to compare the rates of released heat.

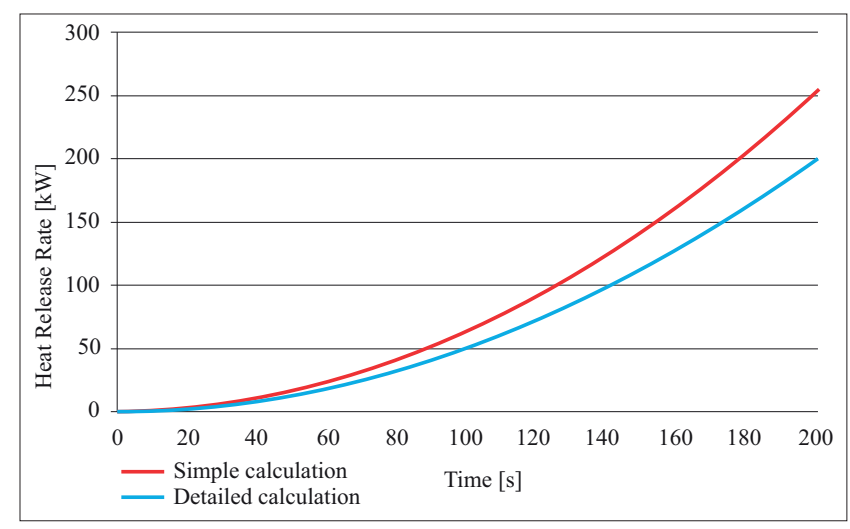

Graph 1 Speed of heat release in time

\section{Simulated persons}

General data about simulated persons which usually occur in practice exercises are stated in this part. Behaviour, motions, and reactions to external influence are considered by the program individually for each person, although he or she belongs to specific data group according to set parameters. Because the simulation is executed in the spaces of a night club, it is supposed that only adult persons are present. It is also supposed that people are aware of the location of the escape exit, since this is the only possible entrance into the object as well.

\section{Number of persons and their detection and reaction time}

Total number of persons in the simulated space of a night club is 69 . Location of fire varies various in practical exercises (see Fig. 6). Thus, it can be supposed that persons start to react to fire in different time intervals due to their location in the space of the night club. Persons in simulations are always divided into three different groups (see Fig. 2) depending on the time intervals of noticing the starting fire and their reaction to it. Their motion time thus starts in time given by the equation (2) (Korhonen and Hostikka, 2009) or even sooner, if they notice the occurrence of smoke in their surroundings and specific height level (the height of $1.6 \mathrm{~m}$ from floor level was chosen for practical simulations).

$$
t_{\text {motion }}=t_{\text {start }}+t_{\text {noticing }}+t_{\text {reaction }} \quad[\mathrm{s}]
$$

The term "start time" means the time from the start of the fire simulation. If there is no delay, the value is standardly 0 .

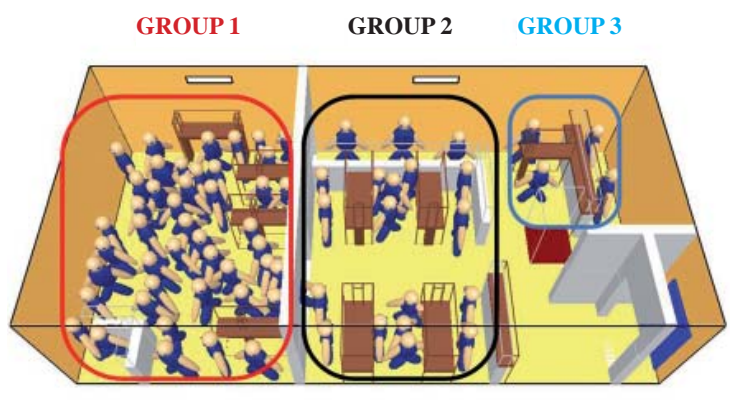

Fig. 2 Division of persons into groups according to different time of the start of evacuation

\section{Reaction of persons to toxicity}

Effect of fire gas emission toxicity in software FDS+Evac is determined using the concept of fractional effective dose called FED. Current version of the programme uses only the concentrations of $\mathrm{CO}, \mathrm{CO}_{2}$ and $\mathrm{O}_{2}$ for the computation of total FED. Concentration of $\mathrm{CO}_{2}$ is taken into account only due to accelerated breathing (hyperventilation), owing to which big amount of dangerous toxic fire emissions gets into human organism. There is no substantiated supposition, though, that the concentration of $\mathrm{CO}_{2}$ would be so high that it would have any toxic effect (over 5 vol. \%).

\section{Results}

\section{Simulation 1}

The computed rate of heat release in time was used in this situation. For the simulation time of $200 \mathrm{~s}$, the highest value of $Q=253 \mathrm{~kW}$ was reached, while fire was located in location 1 (see Fig. 1). Number of persons in the particular group and their different detection and reaction time are stated in Tab. 1. With regard to fire location, the longest reaction and detection time was assigned to group 1 and, vice versa, the shortest one to group 3 . The time intervals are meant from the start of the simulation.

Tab. 1 Description of persons in the simulation 1

\begin{tabular}{|c|c|c|c|c|}
\hline Persons & $\begin{array}{c}\text { Number } \\
\text { of } \\
\text { persons }\end{array}$ & $\begin{array}{c}\text { Interval of } \\
\text { detection } \\
\text { [s] }\end{array}$ & $\begin{array}{c}\text { Interval of } \\
\text { reaction } \\
\text { [s] }\end{array}$ & $\begin{array}{c}\text { Start of } \\
\text { evacuation } \\
\text { [s] }\end{array}$ \\
\hline Group 1 & 46 & $50-55$ & $50-55$ & $100-110$ \\
\hline Group 2 & 19 & $40-50$ & $40-50$ & $80-100$ \\
\hline Group 3 & 4 & $35-40$ & $35-40$ & $70-80$ \\
\hline
\end{tabular}




\section{Progress of simulation 1}

During the simulation, persons react in accordance with expected evacuation start times and there were no visible instances when the evacuation would have started sooner in connection with the detection of smoke. Groups 2 and 3 left the space quite smoothly and even in the narrowed parts of the room no congestions of the escape exit occurred.

Evacuation of group 1, which started its leave lastly, led to a creation of two evacuation streams. Bigger stream consisted of 36 persons, who went from the dance floor towards the exit through the main bar room, i.e. through the aisle among tables. Smaller stream consisted of 10 remaining persons, who went towards the exit through the back aisle. These two streams encountered at the $112^{\text {th }}$ second of the simulation. Subsequently, a delay in the evacuation process occurred due to great number of persons in the narrow space. At the $154^{\text {th }}$ second of the simulation, there were no persons left in the room.

No effect of fire emissions toxicity on escaping persons was recorded during the exercise. Not even in the case when the two mentioned evacuation streams encountered and collide basically right beside the fire site and were situated next to it for about 30 seconds. Due to the intensity of designed fire, the space was significantly filled with smoke until all the people escaped. The simulation started at ambient temperature of $20{ }^{\circ} \mathrm{C}$. During the evacuation, it gradually rose to values of $20-45^{\circ} \mathrm{C}$ in the head level of escaping persons. During the exercise, the fire reached a maximum of $120^{\circ} \mathrm{C}$.

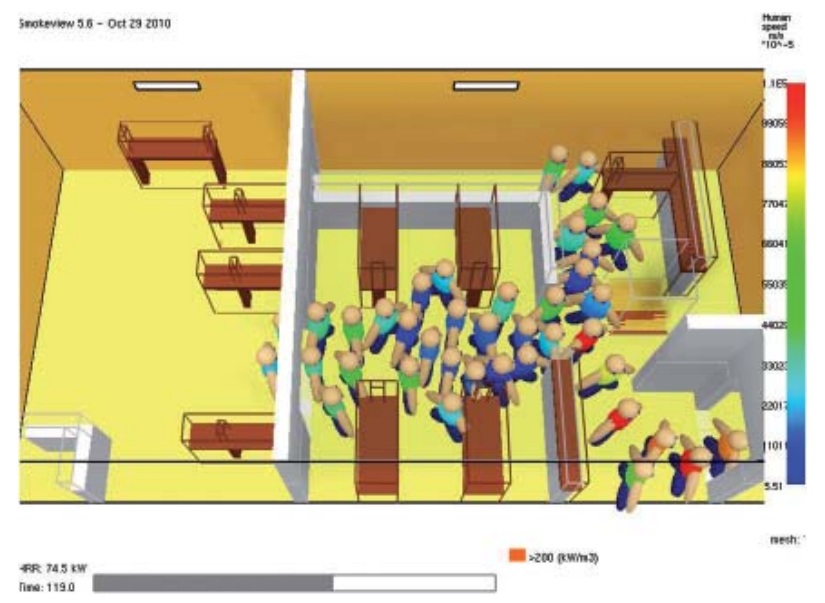

Fig. 3 Speed of motion after the encounter of evacuation streams

Fig. 3 depicts the decrease of escaping people's speed at the time when the two streams of group 1 encountered. The time progress of the simulation and amount of the released heat $[\mathrm{kW}]$ at the given time is visible in the lower part of the picture. Colour scale to the right represents the speed of escaping persons' motion which is coloured according to these values. The scale starts with the value of $5.51 \cdot 10^{-5} \mathrm{~m} . \mathrm{s}^{-1}$ (blue colour) and ends with the value of $1.1 \mathrm{~m} \cdot \mathrm{s}^{-1}$ (red colour).

\section{Simulation 2}

Almost three times higher rate of heat release than in simulation 1 was chosen for this simulation. The reason was to manifest the effect of fire emissions toxicity on escaping persons. If the duration of the simulation was $200 \mathrm{~s}$, then the highest value of $Q=731 \mathrm{~kW}$, while the fire was located in position 2 (see Fig. 1). Numbers of persons in the particular groups and their different detection and reaction times are stated in Tab. 2. Due to fire location, the shortest reaction and detection time was set to group 2 and slightly longer one to groups 1 and 3 .

Tab. 2 Description of persons in simulation 2

\begin{tabular}{|l|c|c|c|c|}
\hline Persons & $\begin{array}{c}\text { Number } \\
\text { of } \\
\text { persons }\end{array}$ & $\begin{array}{c}\text { Interval of } \\
\text { detection } \\
\text { [s] }\end{array}$ & $\begin{array}{c}\text { Interval of } \\
\text { reaction } \\
\text { [s] }\end{array}$ & $\begin{array}{c}\text { Start of } \\
\text { evacuation } \\
\text { [s] }\end{array}$ \\
\hline Group 1 & 46 & $50-55$ & $50-55$ & $100-110$ \\
\hline Group 2 & 19 & $35-40$ & $35-40$ & $70-80$ \\
\hline Group 3 & 4 & $40-50$ & $40-50$ & $80-100$ \\
\hline
\end{tabular}

\section{Progress of simulation 2}

To start with, it's necessary to mention that the use of evacuation obstacle in the fire room was abandoned in this simulation exercise, which of course had some impact on the whole evacuation process. The reason of doing so was that it can serve as an illustrative example of the fact that escaping persons aren't discouraged by higher temperature of fire and they escape through the fire site as well.

In the course of the simulation, people reacted in the same way as in simulation 1 , according to expected evacuation start times, with only one exception. The mentioned exception was one person from group 2, who was located right inside the fire site. That's why this person reacted just on the occurrence of fire and started to escape the room on the $52^{\text {th }}$ second of the simulation, which was 18 seconds sooner than their minimal evacuation start time. The rest of group 2 and group 3 started to escape the room in accordance with their set evacuation start times. In the course of the evacuation of group 2, a reaction to toxic fire emissions was observed in the case of two persons.

Evacuation of group 1 went almost identically as in simulation 1, but with the difference that 25 persons reacted to fire emission toxicity. This was the case of persons who escaped through the main bar room and thus close to the fire or directly over 
it. There were no persons in the room on the $157^{\text {th }}$ second of simulation.

Simulation started at ambient temperature $20^{\circ} \mathrm{C}$. During the evacuation, the temperature gradually rose to values of $20-90{ }^{\circ} \mathrm{C}$ in the head level of evacuating persons. In the course of the exercise, the temperature of fire reached maximum $470{ }^{\circ} \mathrm{C}$.

Fig. 4 illustrates the impact of toxicity on escaping persons. Also it helps to notice added smoke filling in comparison with simulation 1 due to higher rate of heat release. Colour scale on the right side illustrates the values of FED. It starts on the value of 0 (blue colour) and ends with the value of $2 \cdot 10^{-5}$ (red colour).

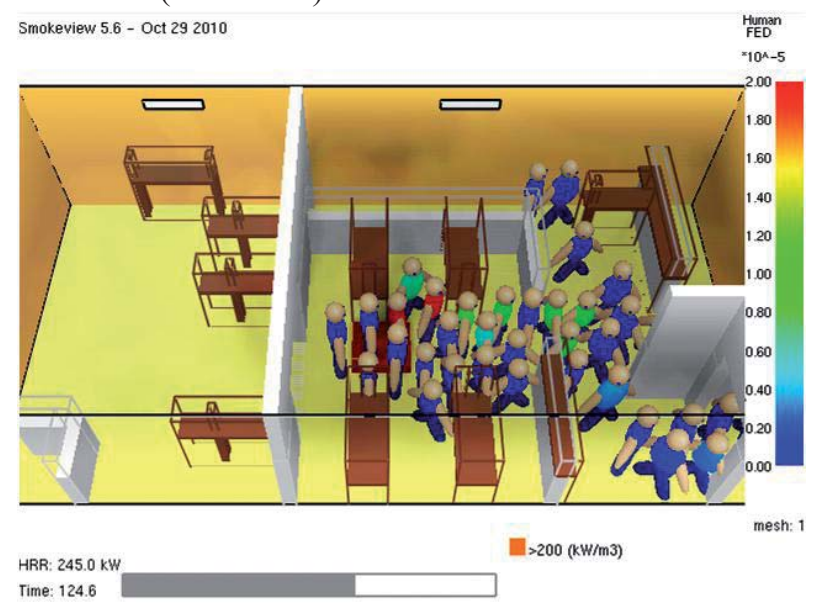

Fig. 4 Response of persons to the toxicity of fire emissions

\section{Discussion}

\section{Evaluation of simulation 1}

There is one positive aspect - all the persons left given space in expected time and their movement wasn't stuck due to some obstacles. Group 1 divided itself into two evacuation streams according to algorithms of simulated persons who tend to seek the shortest way to the escape exit from their specific locations. Given the intensity of the set fire, there wasn't any demonstration of impacts of the fire emissions toxicity on escaping persons. The course of the simulation was then generally trouble-free.

On the other hand, one should mention that so called evacuation obstacle that escaping persons needed to avoid had to be placed in the space of the fire site. Otherwise the persons could move over the space of fire, which would be unrealistic. According to practical examples provided by the authors of FDS+Evac it's clear that the problem can be provisionally solved by placing the fire on elevated site that would be avoided by the persons anyway. We can expect that the imperfection will be eliminated in the future, but we should provide for that when forming the simulation problems for now.

\section{Evaluation of the simulation 2}

In the course of this simulation, all the persons also left the room in expected time and their movement wasn't stuck due to obstacles of fire. Group 1 again divided itself into two evacuation streams which moved identically as in simulation 1. In the course of the simulation, the toxicity had some influence on escaping persons, but the level of toxicity wasn't so high to paralyse in any way the persons on one place (which would happen in the case of exceeding the specific limit of FED in relation with current algorithms of FDS+Evac).

As mentioned earlier, evacuation obstacle in the fire site wasn't used in the course of this simulation. Evacuating persons thus passed smoothly over the fire site, even though there was quite a high temperature, as is well evident from Fig. 4. It can be expected that in real situation at such a high temperatures, people would turn towards a side aisle. But algorithms like FDS+Evac don't operate in this way. Simulated persons mainly react to smoke-filled space, which can affect the choice of escape exit (if there is such an option), and to the value of FED, which they consider as acceptable and continue to evacuate, or the value is so high that people are paralyzed and freeze in place - die.

\section{Conclusion}

Fire can influence the conditions of evacuation considerably. Thanks to the connection between FDS and evacuation module FDS+Evac, it is possible to take into consideration the effects of fire, like, for example, fire temperature, smoke density and its toxicity or the amount of heat radiation. The smoke has an impact on the speed of escaping people's motion. It can also affect the algorithm of choosing the escape exit by its density.

The article was devoted to characteristics, development and objective evaluation of virtual simulations of people's evacuation in fire conditions. The assessment of simulations revealed the positive and negative aspects of the whole evacuation process which partly follow from the algorithms of simulation module FDS+Evac. Making the computer simulations using this software should involve considering the positive and negative findings and taking them into consideration. Simulation can approximate the real situation more closely in this way, which should be its main objective.

Mathematical modelling of evacuating people's behaviour is permanently improving and developing. New findings, resulting from experimental evacuations, are still being discovered. This knowledge is gradually implemented into mathematical equations. 


\section{References}

FOLWARCZNY, Libor, POKORNÝ, Jiř́ (2006). Evakuace osob. Ostrava: Sdružení požárního a bezpečnostního inženýrství, 2006. 125 s. ISBN 80-86634-92-2.

HOSTIKKA, Simo et al. (2007). Development and validation of FDS+Evac for evacuation simulations: Project sumarry report. Finland: VTT Technical research Centre of Finland, 2007. 64 p. ISBN 978-951-38-6982-3.

KORHONEN, Timo, HOSTIKKA, Simo (2009). Fire Dynamics Simulator with Evacuation: FDS+Evac: Technical Reference and User's Guide. Finland: VTT Technical research Centre of Finland, 2009. 91 p. ISBN 978-951-38-7180-2.

KUČERA, Petr, PEZDOVÁ, Zdeňka (2010). Základy matematického modelování požáru. Ostrava: Sdružení požárního a bezpečnostního inženýrství, 2010. 111 s. ISBN 978-80-7385-095-1.

ČSN EN 1991-1-2:2004. Eurokód 1: Zatiženi konstrukci - Část 1-2: Obecná zatížení - Zatižení konstrukcí vystavených účinkům požáru. Praha: Úřad pro technickou normalizaci, metrologii a státní zkušebnictví, $53 \mathrm{~s}$.

ČSN 73 0802:2009. Požární bezpečnost staveb - Nevýrobní objekty. Praha: Úřad pro technickou normalizaci, metrologii a státní zkušebnictví, $122 \mathrm{s.}$ 